\title{
A IMPORTÂNCIA DO TREINAMENTO DE PESSOAL NO AGRONEGÓCIO: UM ESTUDO EM GRANJAS AVÍCOLAS LOCALIZADAS NA REGIÃO DA ALTA PAULISTA
}

Josilene de Jesus Sangalli ${ }^{1}$

Paulo Eduardo Assoni de Souza ${ }^{2}$

Renato Dias Baptista ${ }^{3}$

RESUMO

O agronegócio é um dos setores mais importantes na economia do país e ao mesmo tempo passa por intensas mudanças que redesenham as relações de trabalho. Nesse contexto as ações de gerenciamento de pessoas ocupam um papel fundamental. Pois é por meio delas que as organizações realizam a imprescindível tarefa de contratar e manter pessoas. Este trabalho tem por objetivo identificar as práticas de recursos humanos em 4 granjas localizadas na cidade de Bastos/SP. Por meio de entrevistas realizadas com os gestores foram utilizados questionários semiestruturados e uma pesquisa bibliográfica direcionada ao estudo das práticas de gestão de pessoas. Os resultados mostraram que neste setor são executadas as práticas de recrutamento, seleção e treinamento. Porém observou se que as ações de treinamento precisam avançar para que haja uma otimização de recursos humanos.

PALAVRAS-CHAVE: Recursos humanos, Agronegócio, Treinamento.

\section{THE IMPORTANCE OF PERSONNEL TRAINING IN AGRIBUSINESS : A STUDY IN POULTRY FARMS LOCATED IN THE REGION ALTA PAULISTA}

\footnotetext{
${ }^{1}$ Tecnóloga em Meio Ambiente - UEM, Graduanda em Administração -FADAP/FAP. josisangalli@gmail.com.

${ }^{2}$ Médico Veterinário - UEL, Graduando em Administração - UNESP. pauloassoni@gmail.com

${ }^{3}$ Docente na UNESP/Tupã, Doutor em Comunicação e Semiótica - PUC/SP
} 


\begin{abstract}
Agribusiness is one of the most important sector in our economy and at the same time goes through big changes that reshape the working relationships. In this context, the management action related to people play a very important role. Since organizations put into practice indispensable task to hire and keep people. This paper has the goal to identify human practice resources in 4 laying farms located in the Bastos/SP city. Through interviews carried out with managers with semi-structured questionnaire and a bibliographic research intended to study human practice resources on the laying farms. Results point out that at the moment the sector are executing practices of: recruitment, selection and training. However, was noticed that actions of training needs to advance to optimize human resources.
\end{abstract}

KEY WORDS: Human resources, Agribusiness, Training

\title{
LA IMPORTANCIA DE PERSONAL DE FORMACIÓN EN AGRONEGOCIOS : UN ESTUDIO EN GRANJAS AVÍCOLAS UBICADO EN LA ALTA PAULISTA REGIÓN
}

\begin{abstract}
RESUMEN
El sector de agronegocios es uno de los más importantes del país y que pasa por intensos cambios que rediseñan las relaciones laborales. En ese escenario las acciones de gestión de personas tienen un rol fundamental, pues las organizaciones tienen la tarea de contratar y mantener personas. Esta investigación tiene el objetivo de identificar las prácticas de recursos humanos en 04 granjas ubicadas en la ciudad de Bastos/SP. Por medio de una encuesta realizada con el liderazgo de esas granjas fueran utilizados cuestionarios semiestructurados y una investigación bibliográfica direccionada al análisis de la gestión de personas. Los resultados indicaran que este sector ejecuta principalmente las prácticas de reclutamiento, selección y entrenamiento. Sin embargo, fue observado que las acciones de entrenamiento son las que necesitan de más avanzos para que la optimización de los recursos humanos pueda ocurrir.
\end{abstract}

PALABRAS-CLAVE: Recursos Humanos, Agronegocio, Entrenamiento.

\section{INTRODUÇÃO}

A globalização tem modificado o cenário organizacional, atualmente o concorrente pode ser o vizinho ou mesmo estar do outro lado do mundo. É preciso cada vez mais obter vantagem sobre as organizações tradicionais e as que surgem com inovações, as empresas de sucesso serão as que não terão dificuldades em se adaptar as novas mudanças para ganhar da concorrência (ROBBINS, 2005).

Segundo Chiavenato (2004) o crescimento das organizações demanda maior implemento de tecnologias, recursos financeiros e pessoal. Com o aumento de 
pessoas é necessário tornar-se de forma intensiva a utilização de aspectos de competência para que a empresa possa se sustentar no mercado competitivo.

São as pessoas que atuam e decidem nas organizações, e são estas que realizam praticamente todas as ações na sociedade contemporânea. Para que seja possível entender pessoas e sociedade, conduz-se ao estudo das organizações complexas. As empresas estão em constante mudanças, são influenciadas pelo ambiente e de forma recíproca, interferem nele (LACOMBE, 2012).

De acordo com os estudos de Bohlander e Snell (2013) o capital humano é um recurso intangível, por este motivo as organizações não o administram como se administrassem tecnologia, produtos e cargos. Quando um colaborador deixa a empresa, o capital intelectual o acompanha, com isso, todo investimento que a organização tenha realizado se perde. Neste sentido os gerentes, para deter e garantir estas competências produzem estratégias que objetivam identificar, recrutar e contratar os melhores talentos existentes.

As pessoas passam grande tempo de suas vidas dentro das empresas em que trabalham, entretanto a organização precisa das pessoas e vice versa para que ambas alcancem seus objetivos. Há pouco tempo a relação entre organizações e pessoas era vista como contrária e conflituosa, pois havia uma dualidade de objetivos; empresas buscavam, produtividade, eficácia, redução de custos, aumento no emprego dos recursos físicos e maximização dos lucros (CHIAVENATO, 2004).

Segundo Bohlander e Snell (2013), as empresas precisam de pessoas e viceversa, as organizações estão buscando se adequar as novas formas de administrar o seu capital intelectual para que ambas as partes alcancem seus objetivos e fiquem satisfeitas.

Diante dessa complexidade é preciso gerar um desenvolvimento contínuo dos recursos humanos para que as competências estejam fortalecidas e desenvolvidas.

\section{Os Recursos Humanos no Agronegócio}

As modificações que estão ocorrendo no cenário da economia do mundo têm causado alterações no agronegócio brasileiro. A busca por produtos diversos causa uma fragmentação de mercado, crescendo a exigência dos consumidores por 
qualidade. Por essas mudanças, destaca-se a relevância do capital humano como forma de alcançar vantagens de mercado por meio da gestão estratégica de pessoas, gestão de competências e desempenho e capital intelectual (BATALHA, 2000).

O agronegócio brasileiro é um setor que absorve grande quantidade de mão de obra, incluindo pessoas bem qualificadas e muitas quase sem qualificação, estas pessoas muitas vezes preenchem a necessidade de empreendimentos rurais mais distantes de grandes centros (RIGO et. al., 2007).

Administrar pessoas que atuam em agronegócios aborda várias atividades, incluindo encontrar pessoas com qualificações que se adequem ao mercado competitivo, pois em algumas áreas verifica-se excesso de pessoas e em outras áreas obstáculos em identificar os profissionais que sejam adequados para tal demanda. Devido a estas questões o empreendedor deve se adequar para atrair profissionais que irão desempenhar a função com a produção de qualidade, na hora e medida certa (AMORIM, 2006).

Amorim (2006) enfatiza que para obter êxito em gerir pessoas é indispensável que se estude o mercado de trabalho, as condições e exigências para contratar, avaliar, capacitar e disponibilizar condições de trabalho adequadas. Nesse cenário, é preciso conhecer a realidade para atuar sobre ela, e vencer as variáveis endógenas e exógenas. É indispensável focar as necessidades do indivíduo e outras questões que até então as organizações não estavam preparadas, nem o empresário, o trabalhador e tão pouco o gestor de pessoas (MARRAS, 2011)

Segundo Chiavenato (2004) durante muito tempo acreditava-se que a sustentação do desenvolvimento das empresas fosse o recurso financeiro, porém, hoje se percebe que a falta de habilidades da organização em recrutar e manter as pessoas é o principal desafio. Por este motivo as concepções em relação a gestão de Pessoas estão mudando, atualmente a gestão é baseada em três aspectos conforme Chiavenato (2004):

- Pessoas como seres humanos: Por serem providos de habilidades e competências que são indispensáveis à organização, necessitam ser vistos como pessoas e não somente recursos; 
- Pessoas como ativadores inteligentes de recursos organizacionais: movimentam a organização por meio de inteligência, talento e aprendizagem, dinamizam a organização como agentes ativos e não como agente estável;

- Pessoas como parceiros da organização: investem na organização com dedicação, responsabilidade, esforço, comprometimento e riscos, na esperança de obterem retorno por meio de salários, incentivos financeiros e crescimento na carreira.

Para Bohlander e Snell (2013) os profissionais estão interpretando seu êxito pessoal não somente em recompensas financeiras, mas sim, um equilíbrio entre trabalho e a família. Desta forma administrar os recursos humanos tem se mostrado mais difícil que antes, onde as pessoas buscavam como objetivo somente sobrevivência econômica. É por meio deste novo panorama que se inicia a valorização da função "cuidar do pessoal" (MARRAS, 2011).

A gestão de recursos humanos da empresa irá desenvolver programas de avaliação, capacitação, aperfeiçoamento. Pois cada organização tem suas características, cultura, pontos fracos e fortes, produtos e processos, é necessário que os candidatos se insiram corretamente nas disponibilidades da empresa e contribuam para alcançar os objetivos estratégicos impostos, o que seria a pessoa certa no lugar e momento certo (LACOMBE, 2012).

As ações contínuas e metódicas executadas ou não por setor específico ou especializado, tem como meta preencher e conservar na empresa, funcionários em quantidade e qualidade (GOMES, 1978).

Para Lacombe (2012) as ações de recursos humanos se iniciam por meio da formação da equipe, porém ele salienta que esta formação está sempre ativa. Este planejamento é indispensável para que a organização não desperdice seus recursos financeiros por meio de pessoas que são contratadas e não se enquadram no objetivo da empresa, treinamentos inúteis, equipe mal conduzida, levando a falta de motivação.

As organizações devem disponibilizar as ações básicas e indispensáveis no quesito recursos humanos, que são: atrair, motivar e manter pessoas. Esses 
processos podem ser entendidos como: recrutamento, seleção, treinamento, avaliação de desempenho e programas de incentivo.

Para Bohlander recrutamento é a etapa em que se localiza potenciais candidatos a trabalhar na organização e estimulá-lo a se candidatar em vagas que já estão em aberto ou mesmo antes de abrir.

Existem dois tipos de recrutamento:

- Interno: o processo de busca para o preenchimento da vaga, ocorre dentro da empresa.

- Externo: a procura ocorre em fontes específicas. Isso deve ser feito após a empresa eliminar a possibilidade de que pessoas que estão na empresa ocupem a vaga. (LIMONGI-FRANÇA e ARELLANO, 2002).

Bohlander (2013) afirma que há várias fontes para seleção de candidatos, e que a escolha da melhor alternativa varia de acordo com o cargo. Algumas formas de recrutamento externo são: anúncios (jornais, websites, rádio, pôsteres e mensagem por e-mail), currículos solicitados e não solicitados, indicações de funcionários, empresas de recrutamento, instituições educacionais, associações profissionais, agências de emprego. As principais técnicas utilizadas no processo de seleção são; entrevistas, provas de conhecimento, testes psicológicos, técnicas vivenciais.

Treinamento, segundo Robbins (2005) abrange tudo, desde ensinar de forma simples uma leitura até cursos mais elaborados de liderança empresarial. A avaliação de desempenho é um processo geralmente proporcionado por supervisor ou subordinado com o intuito de auxiliar os funcionários a perceber suas funções, objetivos, expectativas e o sucesso nas atividades que desempenha (BOHLANDER e SNELL, 2013).

Por fim, os programas de incentivo ou programas de reconhecimento, podem se apresentar de várias maneiras, um simples elogio pode ser considerado, atualmente as organizações vem utilizando programas específicos, como, trabalho por produção, mérito, bônus e outros.

Em síntese, os processos básicos para o planejamento de recursos humanos podem ser observados no Quadro 1. 
Quadro 1. Práticas de gestão de pessoas

\begin{tabular}{|l|l|}
\hline Recrutamento & Captação e triagem de profissionais. \\
\hline Seleção & $\begin{array}{l}\text { Escolha do candidato adequado para a } \\
\text { organização, dentre os recrutados. }\end{array}$ \\
\hline Treinamento & $\begin{array}{l}\text { Assimilação a curto prazo com objetivo } \\
\text { de repassar ou reciclar conhecimento, } \\
\text { habilidades ou atitudes. }\end{array}$ \\
\hline Avaliação de Desempenho & $\begin{array}{l}\text { Instrumento gerencial que permite } \\
\text { mensurar resultados obtidos em um } \\
\text { período e área específicos. }\end{array}$ \\
\hline Programas de Incentivo & $\begin{array}{l}\text { Política que liga remuneração aos } \\
\text { esforços e desempenho do funcionário. }\end{array}$ \\
\hline
\end{tabular}

Fonte: Elaborado com base em Marras (2011), Limongi-França e Arellano (2002), Bohlander e Snell (2013).

Diante dos subsistemas citados o presente estudo objetivou dar ênfase as práticas de treinamento e desenvolvimento, elas são consideradas um elemento estratégico para as organizações.

\section{Treinamento e Desenvolvimento}

O principal motivo das empresas treinarem seus membros é alinhar as competências ao nível de desempenho satisfatório, consequentemente os funcionários terão condições de ser mais eficientes em suas atividades, podendo até mesmo desempenhar outras funções ou níveis superiores (BOHLANDER e SNELL, 2013).

Como consequência do treinamento o funcionário irá produzir mais e melhor, sendo isto um retorno de investimento que a empresa aplicou. Além disso, a capacitação se faz necessária pois cada organização tem suas particularidades que o novo funcionário não tem conhecimento logo que é admitido (LACOMBE, 2012).

Bohlander (2013) afirma ainda, que programas de treinamento são para atingir metas e que gerentes devem se atentar as estratégias para adaptar 0 
treinamento a elas. Deve- se realizar uma abordagem sistêmica por meio de quatro fases; levantamento de necessidades, projeto de programa, implementação e avaliação.

O levantamento de necessidades analisa três variáveis; empresa, tarefa e pessoa para que os recursos sejam aplicados de forma efetiva, não havendo desperdícios em treinar pessoas erradas e de forma incorreta (SPECTOR, 2010).

Ainda segundo o autor após a fase anterior os gestores terão a visão mais precisa das necessidades, sendo possível estabelecer quais os resultados querem atingir, esta fase de projeto de programa é baseada em critérios, como os gestores irão posteriormente avaliar este treinamento.

A implementação do treinamento é uma fase importante em que se avalia quais métodos serão aplicados, a escolha dos métodos deve ser alinhada com as habilidades, conhecimento e atitudes dos treinados (BOHLANDER e SNELL, 2013)

A última etapa, descrita como avaliação de treinamento, segundo Spector (2010) consiste em verificar se o programa de treinamento alcançou os objetivos propostos.

\section{Métodos de Treinamento}

No treinamento, várias coisas podem ser consideradas, desde ensinar uma simples leitura a cursos avançado de líderes (ROBBINS, 2005).

Existem vários métodos de treinamento, cada um com suas vantagens, desvantagens, limitações pois pessoas diferentes podem ter um melhor desempenho em perspectivas diferentes, o treinamento deve ser flexível para que os indivíduos se adaptem as exigências do treinador (SPECTOR, 2010).

Os métodos mais utilizados são:

- Treinamento no local de trabalho: é muito utilizado, propõe que a organização gaste de três a seis vezes mais do que em sala de aula. Proporciona experiência prática e interação com o treinador possibilitando bom relacionamento com o indivíduo, é visto por alguns como o melhor método para facilitar o aprendizado. Porém neste tipo há falta de ambiente 
estruturado, pouca aptidão de treinamento dos gerentes, critérios de desempenho pouco definidos (BOHLANDER e SNELL, 2013)

- Treinamento profissionalizante: Utilizado para aprimorar o desempenho na função que o funcionário já exerce, podendo servir de capacitação para outras funções com grau de dificuldade maior, geralmente este treinamento se destina a profissionais técnicos (LACOMBE, 2012)

- Instrução de sala de aula: Permite um grande número de indivíduos que possa ser treinado com o mínimo de instrutores. Esta forma pode ser aplicada em conteúdos que podem ser passados em forma de palestra, dvd, filmes e demonstrações no computador (BOHLANDER e SNELL, 2013).

- Palestra: É uma apresentação feita por um instrutor para um grupo, é um método eficiente, atinge grande número de pessoas. Em situações que o feedback não é necessário a palestra é efetiva (SPECTOR, 2010)

- Orientação: Forma-se uma relação entre funcionários, o mais experiente ajuda o menos experiente a aprender os procedimentos, com isso não só o novo funcionário se beneficia, mas o que ensina desenvolve sua carreira na empresa (SPECTOR, 2010).

As principais formas de treinamento estão esquematizadas no Quadro 2.

\section{Quadro 2. Principais formas de Treinamento de Pessoal}

\begin{tabular}{|l|l|}
\hline Local de trabalho & $\begin{array}{l}\text { Muito utilizado, proporciona interação com } \\
\text { funcionários e aprendizagem prática, } \\
\text { desvantagem devido a custos e falta de } \\
\text { ambiente estruturado. }\end{array}$ \\
\hline Profissionalizante & $\begin{array}{l}\text { Capacitação técnica de funcionário que já } \\
\text { desempenha a função, geralmente funções com } \\
\text { maior grau de dificuldade. }\end{array}$ \\
\hline Instrução sala de aula & $\begin{array}{l}\text { Grande número de indivíduos treinados ao } \\
\text { mesmo tempo, porém nem todos os conteúdos } \\
\text { podem ser passados dessa forma. }\end{array}$ \\
\hline Palestra & Método eficiente, grande número de pessoas, o \\
\hline
\end{tabular}




\begin{tabular}{|l|l|}
\hline & feedback é limitado. \\
\hline Orientação & $\begin{array}{l}\text { Funcionário mais experiente ensina o novo } \\
\text { funcionário, ambos se beneficiam. }\end{array}$ \\
\hline
\end{tabular}

Fonte: baseado em: Bohlander e Snell (2013), Lacombe (2012), Spector (2010)

\section{Avaliação do Programa de Treinamento}

Segundo Spector (2010) um programa de treinamento é finalizado somente quando estiver sido avaliado.

Há várias formas de determinar se o programa de treinamento atingiu os objetivos, porém muitas empresas não avaliam corretamente estes programas.

Existem quatro critérios para analisar o treinamento segundo Spector (2010):

- Reações: mostra o quanto o indivíduo gostou e acredita ter aprendido, esta avaliação é realizada por meio de questionário.

- Aprendizado: determina o que o funcionário aprendeu, o que ele é capaz de demonstrar nos aspectos conhecimento e habilidade adquiridos durante o programa, pode ser avaliado aplicando-se um teste ao final do treinamento.

- Comportamento: referente ao comportamento do indivíduo durante o trabalho, é observado se ele está executando o que foi ensinado.

- Resultados: avalia se os resultados foram alcançados, ou seja, se reduziu custos, aumentou a produtividade.

Segundo estudo de Crepaldi (2013) as práticas de recursos humanos, recrutamento, seleção e treinamento, viabilizam um planejamento na demanda de trabalho. Sistematizar estes processos acrescentam credibilidade e valor como um todo na organização.

\section{Objetivos}

Diante da importância da gestão de pessoas para o desenvolvimento do agronegócio objetivou se identificar as práticas de recursos humanos adotadas em granjas na cidade de Bastos/SP, localizada na região da Alta Paulista visando 
identificar os instrumentos utilizados na metodologia de treinamento e a percepção do gestor em relação ao treinamento.

\section{Metodologia}

Primeiramente a pesquisa contou com uma revisão da bibliografia sobre recursos humanos, e a sua aplicação no agronegócio apresentando o conceito e a sua relevância. No segundo momento optou-se pela pesquisa descritiva que tem por finalidade descrever as características específicas de uma população ou fenômeno ou estabelecer relações entre variáveis, as pesquisas descritivas são comumente mais solicitadas por organizações como instituições de educação e empresas comerciais

(GIL, 2014).

Neste trabalho foi utilizado a técnica de entrevista não estruturada, sendo o entrevistador livre para desenvolver a situação na direção que Ihe for conveniente, possibilitando explorar melhor um aspecto, as perguntas são abertas podendo ser em uma conversa informal (MARCONI e LAKATOS, 2010)

A pesquisa foi realizada no município de Bastos - SP, a cidade possui o maior plantel de aves de postura do país, o que a coloca como a cidade com a maior produção de ovos no Brasil, sendo autointitulada a "capital do ovo". As entrevistas foram realizadas em 4 granjas, por meio de um questionário foram elaboradas 29 perguntas abertas, que foram direcionadas à liderança da produção. Para manter o sigilo das empresas optou-se por identificar as granjas pela letra $G$, de forma que, G1 (granja 1), G2 (granja 2), G3 (granja 3) e G4 (granja 4).

\section{Resultados e Discussão}

Os resultados obtidos nas entrevistas demonstram que as granjas aplicam os métodos de encontrados na literatura, os treinamentos realizados nos locais de trabalho são executados pelos líderes de setor, conhecidos também como encarregados, são eles próprios que treinam o funcionário que entra na empresa. A única granja, G2, que aplica o ensino profissionalizante respondeu que aplica este 
treinamento para os funcionários que executam atividades que demandam maior conhecimento técnico e risco.

As granjas que utilizam o método de palestra, G1 e G3, fazem isso para orientar os funcionários para os riscos de segurança do trabalho. A empresa G4 que utiliza o método de instrução na sala de aula, executando esse processo na periodicidade de 15 dias, porém, somente os líderes de setores fazem o treinamento.

Os respondentes da G1, G2 e G3 disseram não haver periodicidade, somente no momento que se percebe a necessidade é realizado. Como também foi observado no estudo de Rezende et al, (2012), os empresários acreditam que os funcionários que entram e são instruídos alcançarão os resultados por meio da execução contínua das atividades.

Os respondentes das granjas $\mathrm{G} 1, \mathrm{G} 2$, disseram que preferem contratar um funcionário que já possui a experiência no trabalho, para que não haja custos em treiná-lo, o que é muito comum na região que possui grande número de granjas, na maioria das vezes o funcionário que se candidata já trabalhou em outras.

O respondente da G3 respondeu que prefere que a pessoa não tenha experiência, pois os que têm podem não admitir mudar o que já sabem. O respondente $\mathrm{G} 4$ disse que é indiferente a preferência por funcionários que possuem experiência.

Sobre a avaliação do treinamento G1, G2 e G3 utilizam os mesmos métodos, observando se os funcionários estão executando o trabalho da forma que aprenderam e por meio dos resultados, ou seja, maior qualidade do ovo. A granja G4 aplica somente o método, comportamento o respondente disse que a empresa pouco se atenta em verificar se o funcionário aprendeu o que lhe foi ensinado, pois a maioria dos funcionários são antigos muitos estão há mais de 20 anos então a empresa não vê a necessidade de mensurar esse aspecto.

Alguns aspectos do estudo de Rigo et al., 2007 se assemelham a este em que em algumas granjas há a predominância de produtores familiar, inclusive morando na propriedade junto a granja, outro aspecto observado foi o fato de os empresários não exigirem nível de instrução para os candidatos. Porém o respondente G3 disse encontrar dificuldades em contratar pessoas que saibam 
manusear máquinas modernas. A esquematização dos métodos de treinamento e avaliação de treinamento aplicado estão demostrados no Quadro 3.

Quadro 3. Caracterização da empresa e métodos de treinamento.

\begin{tabular}{|l|c|c|c|c|}
\hline & G1 & G2 & G3 & G4 \\
\hline $\begin{array}{l}\text { Quantidade } \\
\text { funcionários }\end{array}$ & 100 & 60 & 170 & 200 \\
\hline $\begin{array}{l}\text { Quantidade aves } \\
\text { alojadas }\end{array}$ & 500 mil & 500 mil & 1 milhão & 850 mil \\
\hline $\begin{array}{l}\text { Tempo de vida } \\
\text { empresa }\end{array}$ & 46 anos & 50 anos & 40 anos & 42 anos \\
\hline
\end{tabular}

\begin{tabular}{|l|c|c|c|c|}
\hline & G1 & G2 & G3 & G4 \\
\hline Local de Trabalho & $\mathbf{X}$ & $\mathbf{X}$ & $\mathbf{X}$ & \\
\hline Profissionalizante & & $\mathbf{X}$ & & \\
\hline Instrução sala aula & & & & $\mathbf{X}$ \\
\hline Palestra & $\mathbf{X}$ & & $\mathbf{X}$ & \\
\hline Orientação & & & $\mathbf{X}$ & $\mathbf{X}$ \\
\hline
\end{tabular}

Métodos de avaliação de treinamento

\begin{tabular}{|l|c|c|c|l|}
\hline & G1 & G2 & G3 & G4 \\
\hline Reação & & & & \\
\hline Aprendizado & & & & \\
\hline Comportamento & $\mathbf{X}$ & $\mathbf{X}$ & $\mathbf{X}$ & $\mathbf{X}$ \\
\hline Resultados & $\mathbf{X}$ & $\mathbf{X}$ & $\mathbf{X}$ & \\
\hline
\end{tabular}




\section{Considerações Finais}

No estudo foi observado que as granjas utilizam as práticas de recursos humanos para contratar e manter pessoas, porém no processo treinamento necessitam avançar em alguns aspectos, visto que elas executam o treinamento somente quando verificam a necessidade, sendo isto um indicativo de que a fase de levantamento de necessidade precisa ser melhor analisada, pois é uma etapa indispensável para que os resultados sejam atingidos, e não seja desperdiçado recursos.

Outro aspecto é que os gestores não têm a percepção de que o treinamento deve ser realizado de forma contínua para que os conhecimentos não se tornem obsoletos. Por mais que o funcionário esteja há bastante tempo na mesma função ou na empresa é importante que haja uma capacitação de forma contínua.

A gestão de pessoas dentro da empresa deve ser vista como um processo em que irá resultar em desenvolvimento e sucesso de todos da organização, sendo necessário um planejamento, estratégico em todas as etapas. Pois o funcionário melhor capacitado sente se valorizado, sendo esta percepção refletidas de forma positiva em suas atividades.

Para pesquisas futuras seria relevante compreender outros aspectos que procedem o treinamento, como, avaliações de desempenho e programas de incentivo, estes estudos facilitam a compreensão dos gestores na elaboração de programas na organização e em tomadas de decisão.

\section{Referências Bibliográficas}

AMORIM, T. N. G. F. Gestão de pessoas no agronegócio. In: Callado, A. A. C. (Org). Agronegócio. 1. ed. São Paulo: Atlas, 2006.

BATALHA, M.O. et al. Recursos humanos para o agronegócio brasileiro. Brasília: CNPq, 2000. BOHLANDER, G.; SNELL, S. Administração de recursos humanos. São Paulo: Cengage Learning, 2009.

CHIAVENATO, I. Gestão de pessoas: o novo papel dos recursos humanos nas organizações. 2 ed. Rio de Janeiro: Elsevier, 2004. 
CREPALDI, M. L. S.; ECHEVERRIA, E.L.; BIANCHI, E. O Recrutamento, seleção e treinamento e seu impacto no desempenho da função na linha de produção. Revista de Administração Faipe, Cuiabá, MT, v.3, n.1, 2013.

GIL, A.C. Métodos e Técnicas de Pesquisa Social. 6 ed. São Paulo: Editora Atlas, 2014.

GOMES, J. F. Administração de recursos humanos e desenvolvimento organizacional. Revista de Administração de Empresas, Rio de Janeiro, FGV, 4(18), out. / dez. 1978. Disponível em: http://www.scielo.br/scielo.php?pid=S0034-75901982000100003\&script=sci arttext. Acesso em 26 abril 2015.

LACOMBE, F.J.M. Recursos Humanos: princípios e tendências. 2ed. São Paulo: Saraiva, 2012.

LIMONGI-FRANÇA, A. C; ARELLANO, E.B. Os processos de Recrutamento e Seleção. In: FLEURY, M. T. L. (Org). As pessoas na organização. 11. ed. São Paulo: Gente, 2002.

MARCONI, M. A.; LAKATOS, E. M. Fundamentos da metodologia científica. 7. ed. São Paulo: Atlas, 2010.

MARRAS, J. P. Administração de recursos humanos: do operacional ao estratégico.14. ed. São Paulo: Saraiva, 2011.

REZENDE et. al. O treinamento de pessoal em organizações de pequeno porte: um estudo de caso na cidade de Maringá. Revista Ciências Administrativas da Universidade de Fortaleza, Fortaleza, v. 8, n. 2, 2012.

RIGO et. al. Gestão de pessoas no agronegócio: uma pesquisa preliminar no Vale do São Francisco. In: CONGRESSO DA SOCIEDADE BRASILEIRA DE ECONOMIA, ADMINISTRAÇÃO E SOCIOLOGIA RURAL, 45., Londrina. Anais... Londrina: UEL, 2007.

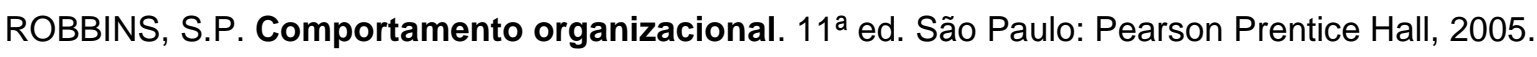

SPECTOR, P. E. Psicologia nas Organizações. 3ed. São Paulo: Saraiva, 2010. 